Gönderim Tarihi: 25.05.2018 Kabul Tarihi: 28.12.2018

\title{
SAHIPLIKK YAPISI VE SERMAYE KARARLARI ARASINDAKİ İLIŞKİNİ İNCELENMESİ: BİST İMALAT SEKTÖRÜ ÖRNEĞİ
}

\author{
Hüseyin TEMIZ* \\ Elçin DALKILIÇ**
INVESTIGATION OF THE RELATIONSHIP BETWEEN OWNERSHIP STRUCTURE AND CAPITAL DECISIONS: BIST MANUFACTURING CASE \\ $\ddot{O} z$
}

\begin{abstract}
$\mathrm{Bu}$ çalışmanın amacı firma sermaye yapısı ile sahiplik yapısı arasındaki ilişkilerin incelemesidir. Bu amaç doğrultusunda BİST'de işlem gören İmalat Sektörü firmaları örneklem grubu olarak belirlenmiştir. Çalışmada örneklem firmalarına ait 2012-2016 yıllarını kapsayan 137 firmaya ait 685 firma-yıl verisi kullanılmıştır. Çalışma kapsamında sermaye yapısı kararları ve sahiplik yapısı arasındaki ilişkilerin farklı açılardan ele alınması amacıyla altı hipotez test edilmiştir. Elde edilen bulgulara göre en büyük ortak oranı, kurumsal ortak ve yabancı ortak payı ile firmaların borçluluk durumunu gösteren finansal kaldıraç oranı arasında negatif ve istatistiksel olarak anlamlı ilişkiler tespit edilmiştir. Diğer taraftan elde edilen bulguların, firmaların halka açıklık oranının artmasının finansal kaldıraç oranını azalttığı hipotezini desteklemediği görülmüştür.
\end{abstract}

Anahtar Kelimeler: Sermaye Yapısı, Sahiplik Yapısı, Kurumsal Ortak, Yabancı Ortak.

\begin{abstract}
The aim of this study is to examine the association between capital structure and ownership structure. In this juncture, the Manufacturing Sector firms that are listed on Borsa Istanbul are identified as the sample group. The 685 firm-year data of 137 firms' covering the years 2012-2016 are used in this study. Within the scope of this study, six hypotheses were tested in order to discuss the relationship between capital structure decisions and ownership structure from different perspectives. According to the obtained results, there is negative and statistically significant relationships between the largest shareholders ratio, the corporate shareholders ratio and foreign shareholders ratio and the financial leverage which indicates the indebtedness of firms. On the other hand, the
\end{abstract}

\footnotetext{
* Dr. Öğr. Üyesi, Bozok Üniversitesi, İİBF, Sağlık Yönetimi Bölümü, e-posta: huseyin.temiz@bozok.edu.tr.

** Arş. Gör., Bozok Üniversitesi, İIBF, İşletme Bölümü, e-posta: elcin.eren@bozok.edu.tr.
} 
obtained findings do not support the hypothesis that firms' free float ratio reduce financial leverage ratio.

Keywords: Capital Structure, Ownership Structure, Corporate Shareholder, Foreign Shareholder.

\section{Giriş}

Sermaye yapısı genel olarak firma faaliyetlerinin finansmanında uygulanan özkaynak ve yükümlülük bileşenini ifade etmektedir. Bu bakış açısıyla sermaye yapısı firmanın kendisini hangi kaynaklarla finanse ettiğinin bir ifadesi olarak değerlendirilebilir. Söz konusu bileşen borç ve özkaynağın finansmanının farklı özelliklere sahip olması bakımından firmalar açısından önem taşımaktadır. Firmaların kaynak bileşimini oluşturmak için gerekli kaynakları nereden ve ne şekilde karşılayacakları ile ilgili kararlar da, sermaye yapısı kararları olarak ifade edilmektedir (Kartal 2017: 426). Firma yöneticileri faaliyetlerin devamını sağlamak amacıyla ihtiyaç duyulan varlıkları finanse ederken, bilançonun kaynak yapısını da oluşturmaktadır (Sayman 2012: 153).

Sermaye yapısı, firma etkinliğini büyük ölçüde etkileyecek olan kurumsal yönetişimin en önemli özelliklerinden biridir (Zhaoguo ve Xiaoxia 2009: 4564). Yöneticiler ve paydaşlar ile kontrol eden ve azınlık paydaşları arasındaki çıkar çatışmaları kurumsal yönetişim literatürünün en önemli konularındandır (Driffield, Mahambare ve Pal 2007: 536). Firma sahipleri ve yöneticilerinin firmayla ilgili beklentileri farkl111k göstermektedir. Beklentilerin farklı olması alınan kararların da farklı olmasına yol açmaktadır. Firma sahipleri faaliyetlerin devam etmesi için ihtiyaç duyulan varlıkların finansman kararlarını alırken sermaye yapısını da belirlemektedirler. Sermaye yapısı da paydaşların elde edeceği getiriyi ve firma değerini etkilemesi bakımından firma açısından önemli bir karar olarak değerlendirilmektedir. Borç ağırlıklı bir sermaye yapısının firmaya ait risk ve iflas ihtimali algısını arttırması ve borçtan kaçınarak özkaynak araçları yoğun bir sermaye yapısının da piyasada firmanın kendi iradesi dışında yönetilmesi algısı oluşturabilir.

Firma sermaye yapısı kararlarını etkileyen faktörler literatürdeki pek çok çalışmada ele alınmıştır. Yapılan araştırmalardan elde edilen bulgular kapsamında firma sermaye yapısı kararlarında karlılık, büyüklük, likidite gibi firma karakteristiklerinin etkili olduğu ifade edilebilir (Zhaoguo ve Xiaoxia 2009; Brailsford, Oliver ve Pua 2002; Sayman 2012). Sermaye yap1s1 kararlarında firma karakteristiklerinin yanı sira sahiplik yapısının da etkili olduğu değerlendirilmektedir. Örneğin, vekalet teorisine göre hakim ortağın firma yönetimini büyük ölçüde kontrol altına alacağı ve 
finansman kararlarında vekalet sorununu kontrol etmek amacıyla borç ağıllıklı davranacağı beklenmektedir (Ayrıçay ve Kalkan 2013: 168). Bu noktadan hareketle, firma sermaye yapısı ile sahiplik yapısının ilişkili olacağı da değerlendirilmektedir.

Demsetz ve Lehn (1985: 1176) firmaların sahiplik yapılarının değer maksimizasyonu ekseninde, bulunduğu koşul ve sektöre göre farklılaştığını ifade etmiştir. Sermaye yapısı kararları gibi, bir firmanın sahiplik yapısının da firma değerini maksimize edecek şekilde belirlendiği sonucuna ulaşan çalışma sonuçları, firma sermaye yapısı ve sahiplik yapısı arasındaki ilişkiler hakkındaki soruları ortaya çıkarmaktadır.

Firma paylarının büyük bir bölümünün belirli kişilerin elinde bulunduğunda mülkiyet yoğunluğunun fazla olması durumu ortaya çıkmaktadır. Bu sebeple mülkiyet yoğunluğunun fazla olduğu ve buna karşılık halka açıklık oranının düşük olduğu firmalarda paydaşların aynı zamanda yönetici olma olasılığı yüksektir (Bayrakdaroğlu 2010: 14). Sahiplik yapısı özkaynaklar ile açıklanabileceği gibi pay sahiplerinin niceliksel/niteliksel özellikleri ve yönetimle ilişkileri göz önüne alınarak tanımlanabilir (Sayman 2012: 76). Bu haliyle sahiplik yapısından kasıt, bir kişinin ya da küçük bir grubun sahip olduğu firmalardan çok ortaklı firmalara ve hatta kurumsal/yabancı ortakliklara kadar uzanan bir çeşitliliği ifade etmektedir.

Sahiplik yapısı türleri, aile işletmesi, kurumsal ortak varlığı, yabancı ortak sahipliği ve yönetici sahipliği şeklinde ifade edilebilir. Firmaların sahiplik yapısı ile firma kontrolü arasında doğrusal bir ilişki vardır. Diğer bir ifade ile sermaye yoğunluğu arttıkça hâkim paydaşın firmadaki kontrolü artmaktadır. Hâkim paydaşlar belirli bir kişi olabileceği gibi aile, kurumsal yatırımc1 veya yabancı sahipliği şeklinde olabilmektedir (Doğan 2016: 158). Sahiplik yapısı, paydaşların özellikleri, yönetimle olan ilişkileri ve paydaşların firma kontrolünü elinde bulundurup bulundurmadığıyla ilgili bir kavram olarak tanımlanabilir.

Firmalarda sahiplik yapısı, sermayeyi kimlerin temsil ettiği ve sermaye paylarının büyüklüğünü ifade eder ve firma yönetimine sermayenin büyük bölümüne sahip olanlar tarafından yön verildiği bir gerçektir. $\mathrm{Bu}$ sebeple sahiplik yoğunluğu arttıkça firma yönetimi ve kontrolü büyük paydaşların elinde olmaktadır (Doğan 2016a: 51). Kuşkusuz her sahiplik yapısının yönetim sürecinde farklı motivasyonları söz konusudur. $\mathrm{Bu}$ motivasyonların sermaye kararları üzerindeki etkileri de, sermaye kararlarının paydaş ve firma değeri üzerindeki etkileri dikkate alınarak incelenmesi önem taşıyan bir konu olarak değerlendirilmektedir. 
$\mathrm{Bu}$ doğrultuda çalışmanın amacı BIST İmalat Sektöründe faaliyet gösteren firmaların sahiplik yapıları ve sermaye yapıları arasındaki ilişkinin incelenmesidir. Literatürde bu kapsamda yapılmış çalışmalar mevcuttur. Elde edilen sonuçlar derlendiğinde dönemsel, sektörel ve bölgesel farklılıkların olduğu dikkat çekmektedir. Ayrıca çalışmalarda genellikle sahiplik yapısı kısıtlı temsilcilerle ölçülmektedir. Bu çalışmayı diğer çalışmalardan ayıran belirgin özellik ve temel motivasyon güncel verilerin kullanılarak sahiplik yapısının birden çok temsilci ile ölçülmesidir. Bu sayede sahiplik yapısı ve sermaye yapısı arasındaki ilişkiler güncel veriler dahilinde kapsamlı olarak incelenmiş olacaktır.

$\mathrm{Bu}$ çalışma, beş bölümden oluşmaktadır. İkinci bölümde sahiplik yapısı ve sermaye yapısı arasındaki ilişkiyi inceleyen literatürde yer alan çalışmalara yer verilmiştir. Üçüncü bölümde çalışmanın amacı kapsamında oluşturulan veri seti ve değişkenler açıklanmıştır. Dördüncü bölümde verilerin analizi ve bulgulara yer verilmiş ve beşinci bölümde sonuç ve öneriler sunulmuştur.

\section{Literatür Taraması}

Sermaye kararları ve sahiplik yapısı arasındaki ilişki, literatürde önemli bir yere sahiptir. Söz konusu önemin nedeni, firmaların sermaye yapısı kararlarına etki eden faktörlerin tespit edilmesinin yanında, sahiplik yapısının bu kararlar üzerindeki etkisinin görülme arzusudur. Sahip, yönetici ve üçüncü taraflar kuşkusuz bulundukları pozisyona ait getirilerin maksimize edileceği kararların alınmasını isteyeceklerdir. Bu noktada firmaların sermaye yapısı kararlarının anlaşılması ve sermaye yapısı kararları ile ilişkili olan olguların araştıılması önem taşımaktadır.

Konu ile ilgili yapılan uluslararası çalışmalardan biri Kester (1986) çalışmasıdır. Bu çalışmada Japonya'daki üretim firmalarının sermaye ve sahiplik yapıların analiz ederek bu firmaları ABD firmaları ile karşılaştırılmıştır. Bunun için 27 ayrı sektörde 344 Japon firması ve 452 ABD firmasının kesitsel verileri kullanılmıştır. Analiz sonucunda Japon firmalarının sermaye ve sahiplik yapısının, ABD'de faaliyet gösteren kıyas firma uygulamalarına göre önemli miktarda borç finansmanı kullanmaya elverişli olduğu tespit edilmiştir.

Pushner (1995) çalışmasında, sahiplik yapısının kaldıraç üzerindeki etkisini araştırmak için 1976-1989 yılları arasında Japonya'da faaliyet gösteren firmalar üzerine bir araştırma yapılmıştır. Kurumsal yatırımcıların sahip olduğu firmaların diğer firmalara göre sermaye yapılarını daha az yabancı kaynak kullanarak finanse etmeyi tercih ettikleri ifade edilmiştir. Firma içi sermaye sahipliğinin kaldıraç düzeyi 
üzerinde güçlü pozitif etkilerinin olduğu tespit edilmiştir. Ayrıca kaldıraç düzeyi yüksek olan firmaların üretkenliklerinin düşük olduğu ifade edilmiştir.

Brailsford vd. (2002) çalışmasında, sermaye yapısı ve sahiplik yapısı arasındaki ilişki 1989-1995 yılları arasında Avustralya Borsası'nda işlem gören firmalar kapsamında incelenmiştir. Elde edilen bulgulara göre, dış hakim ortaklık payı ile finansal kaldıraç oranı arasında pozitif ilişki tespit edilmiştir. Ancak söz konusu pozitif ilişkinin yönetici ortak oranına göre değişim gösterdiği belirtilmiştir. Yönetici ortak oranı ve finansal kaldıraç oranı arasında ise doğrusal olmayan pozitif bir ilişki olduğu ifade edilmiştir. Bu sonuçların da hakim ortağın aktif izleme özelliği ve çıkarların yakınsanmasıyla uyum içerisinde olduğu değerlendirilmiştir.

Santos, Moreira ve Vieira (2014), 2002-2006 yılları arasinda 12 Bat1 Avrupa ülkesinde 649 firma ile yapılan çalışmada sahiplik yapısı ile kaldıraç oranı arasındaki ilişki incelenmiştir. Sermaye yoğunlaşması ile kaldıraç oranı arasında negatif ve anlamlı ilişkiler tespit edilmiştir. Ayrıca aile firmalarının kaldıraç oranı üzerinde yasal çevre ve kurumsal ortama göre değişkenlik gösteren önemli bir etkisinin olduğu ifade edilmiştir.

Driffield vd. (2007) çalışmasında, sahiplik yapısının sermaye yapısı ve firma değeri üzerindeki etkisi 1994-1998 yılları arasında dört doğu Asya ülkesinde işlem gören finansal olmayan firmaların verilerini kullanarak ölçülmeye çalışılmıştır. Elde edilen sonuçlara göre sermaye yoğunluğu artan firmaların yani sahiplik yapısı daha az kişinin elinde olan firmaların sermaye yapısının daha çok yabancı kaynaklardan oluştuğu belirtilmiştir.

Li vd. (2009) 2000-2004 yılları arasında Çin'de faaliyet gösteren firmalar için yapılan çalışmada kurumsal yatırımcı ve sermaye yapısı arasındaki ilişki incelenmiştir. Çalışma sonucunda, kamu sahipliğinin finansal kaldıraç oranı ile pozitif ilişkili olduğu, yabancı yatırımeı sahipliği ve finansal kaldıraç oranı arasında ise negatif ilişki olduğu tespit edilmiştir. Ayrıca, yabancı yatırımcı sahipliğindeki firmaların daha az yabancı kaynak kullandığı tespit edilmiştir.

Margaritis ve Psillaki (2010) çalışmasında sermaye yapısı, sahiplik yapısı ve firma performansı arasındaki ilişki incelenmiştir. Bu çalışmada Fransız üretim firmalarının verileri kullanılmıştır. Elde edilen bulgulara göre sermaye yoğunluğu arttıkça firmaların finansman konusunda daha fazla borçlanmaya yöneldikleri tespit edilmiştir. Bunun yanı sıra çalışmada genel olarak sahiplik yapısı türlerinin sermaye yapısında etkili olmadığı değerlendirilmiştir. 
Céspedes, González ve Molina (2010) çalışmasında, yedi ülkeyi kapsayan 1996-2005 yılları arasında faaliyet gösteren Latin Amerika firmalarının sahiplik yoğunluğunun sermaye yapısı kararlarını nasıl etkilediği tespit edilmeye çalışılmıştır. Çalışma sonucunda finansal kaldıraç oranı ve sahiplik yapısı arasında pozitif ilişki tespit edilmiştir. Ayrıca sermaye yoğun firmaların, yönetim kontrolünü kaybetmemek için daha çok yabancı kaynakla finansmanı tercih ettikleri ifade edilmiştir.

Konuyla ilgili ulusal çalışmalardan biri olan Sayman (2012) çalışmasında sermaye yapısı ile sahiplik yapısı arasındaki ilişki araştırılmıştır. Bu çalışmada 1998-2009 yılları arasında Borsa İstanbul'da işlem gören imalat firmalarının verileri kullanılmıştır. Çalışma sonucunda firmaların halka açıklık oranı arttıkça sermaye yapısında yabancı kaynak oranının azaldığı tespit edilmiştir. Ayrıca çalışma sonucunda sahiplik yapısının sermaye yapısı kararları üzerinde etkili olduğu ifade edilmiştir.

Ege ve Topaloğlu (2013) çalışmasında sahiplik yapısının sermaye yapısı kararları üzerindeki etkisini ortaya çıkarmak için Borsa İstanbul 30 Endeksi'nde 2009-2015 döneminde faaliyet gösteren firmaların verileri analiz edilmiştir. Analiz sonucunda sahiplik yapısı değişkenleri ile sermaye yapısı kararları arasında istatistiksel olarak anlamlı herhangi bir ilişki tespit edilmemiştir.

Büyükmert (2015) çalışmasında firmalardaki sahiplik yapısının sermaye yapısı ve karlılık üzerindeki etkisini, 2010-2013 yılları arasında BİST'de işlem gören 133 firma verisi kullanarak araştırılmıştır. Çalışma sonucunda genel olarak sahiplik yapısının sermaye yapısı üzerinde etkili olduğu sonucuna ulaşılmıştır. Aile firmalarının diğer firmalara göre daha yüksek oranda yabancı kaynak kullandıkları ve kısa vadeli yabancı kaynak kullanımını daha çok tercih ettiklerini destekleyen bulgular elde edilmiştir.

Erdoğan (2016) çalışmasında sahiplik yapısı ve sermaye yapısı kararları arasındaki ilişkiyi incelemek amacıyla 2002-2010 yılları arasında BİST'de işlem gören 162 işletme ele alınmıştır. Çalışma sonucunda sahiplik yapısı ile sermaye yapısı kararları arasında pozitif ilişki tespit edilmiştir. Sahiplik yoğunluğu arttıkça hakim paydaşların sermayenin hisse yoluyla dağıtılmaması ve bunun yerine borçlanma yoluyla finansman oluşturma yoluna gittikleri tespit edilmiştir.

Karacaer, Temiz ve Güleç (2016) çalışmasında imalat sektöründe sermaye yapısının önemli belirleyicileri araştırılmıştır. Çalışmada 20052014 yılları arasında BİST'de işlem gören 131 firmanın verisi analiz edilmiştir. Araştırma sonucunda firma büyüklüğü değişkeni ile finansal kaldıraç oranı arasında pozitif ilişki tespit edilmiştir. Ayrıca karlılık ve 
likidite değişkenleri ile finansal kaldıraç oranı arasında negatif ilişki elde edilmiştir.

Kurumsal sahiplik ve sermaye yapısı arasındaki ilişkinin araştırıldığı Çinko ve Kasaboğlu (2017) çalışmasında da 2005-2013 yılları arasında BİST'de işlem gören 150 firmaya ait veriler kullanılmıştır. Araştırmadan elde edilen bulgulara göre finansal kaldıraç oranı ile kurumsal sahiplik oranı arasında anlamlı ve negatif ilişki olduğu tespit edilmiştir.

\section{Veri Seti, Yöntem ve Değişkenlerin Tanımlanması}

$\mathrm{Bu}$ çalışmada firmaların sahiplik yapıları ile sermaye yapısı arasındaki ilişkiler sahiplik yapılarının farklı temsilcilerle ölçülmesi yoluyla incelenmiştir. Çalışma kapsamında yapılan analizlerde 2012-2016 yılları arasında BİST'de işlem gören imalat firmalarının verileri kullanılmıştır. Finansal veriler Datastream veri tabanından ve firmaların sahiplik yapılarına ilişkin bilgiler de Kamuyu Aydınlatma Platformu (KAP)'dan temin edilmiştir. İnceleme döneminin 2012 yılından başlama nedeni, KAP bünyesinde firmaların son beş yıla ait sahiplik yapılarına iliş̧in bilgilerine ulaşılabilir olmasıdır. Çalışmada örneklem grubunu oluşturan firmalardan eksik gözleme sahip olanlar analiz dışı bırakıldığında toplam 137 firmaya ait 685 firma-yıl verisi ile analizler yapılmıştır. Verilerin analizi için Eviews 9 programı kullanılmıştır. Firmaların sahiplik yapıları ve sermaye yapısı kararları arasındaki ilişkinin incelenmesinde aşağıdaki model kullanılmıştır (Çinko ve Kasaboğlu 2017; Ege ve Topaloğlu 2013):

$F L_{i t}=\alpha_{0}+\beta_{1} X_{k}+\beta_{2} R O A_{i t}+\beta_{3}$ Size $_{i t}+\beta_{4}$ Growth $_{i t}+\varepsilon_{i t}$

$X_{k}=E B O, E B 3 O, E B 5 O, H A O, K O$ ve $Y O$ olarak ifade edilen ve her biri firma sahiplik yapısının temsilcisi olan değişkenlerin ortak ifadesidir.

\subsection{Modelde Kullanılan Değişkenler}

Çalışmanın temel amacı firmaların sahiplik yapılarındaki farklı bileşenler ve sermaye yapısı arasındaki ilişkilerin incelenmesidir. $\mathrm{Bu}$ doğrultuda kurulan modelde bağımlı değişken sermaye yapısının temsilcisidir. Sermaye yapısını ölçmek için literatürde çeşitli ölçüm yöntemleri geliştirilmiştir. Bunlardan en sık kullanılanı finansal kaldıraç olarak bilinen toplam yabancı kaynakların toplam varlıklara oranıdır (Driffield, Mahambare ve Pal 2007; Margaritis ve Psillaki 2010; Céspedes, González ve Molina 2010). Bağımsız değişkenler olarak ise literatürde yer alan kontrol değişkenlerinin yanı sıra çalışma amacı doğrultusunda firma sahiplik yapısının temsilcileri olarak en büyük ortak, en büyük üç ortak, en büyük beş ortak oranı, halka açıklık oranı, kurumsal ortak ve yabancı ortağın sermayedeki payı bağımsız değişkenler olarak 
belirlenmiştir. Modelde yer alan değişkenler aşağıdaki şekilde ifade edilebilir:

Tablo 1: Modelde Kullanılan Değişkenler

\begin{tabular}{|c|c|c|}
\hline Değişkenler & Terimler & Hesaplanma Şekli \\
\hline $\begin{array}{l}\text { Finansal } \\
\text { Kaldıraç }\end{array}$ & $\mathrm{FL}_{\mathrm{it}}$ & $\begin{array}{l}\text { i firmasının t yılındaki toplam borçlarının toplam } \\
\text { varlıklara oranı }\end{array}$ \\
\hline $\begin{array}{ll}\text { En } & \text { Büyük } \\
\text { Ortak } & \end{array}$ & $\mathrm{EBO}_{\text {it }}$ & $\begin{array}{l}\text { i firmasının t yılındaki sermayesi } \% 5 \text { 'den büyük } \\
\text { en büyük ortağının sermaye payının toplam } \\
\text { sermayeye oranı }\end{array}$ \\
\hline $\begin{array}{l}\text { En Büyük Üç } \\
\text { Ortak }\end{array}$ & $\mathrm{EB} \mathrm{O}_{\mathrm{it}}$ & $\begin{array}{l}\text { i firmasının t yılındaki sermayesi } \% 5 \text { 'den büyük } \\
\text { en büyük } 3 \text { ortağının sermaye payının toplam } \\
\text { sermayeye oranı }\end{array}$ \\
\hline $\begin{array}{l}\text { En Büyük Beş } \\
\text { Ortak }\end{array}$ & $\mathrm{EB5O}_{\text {it }}$ & $\begin{array}{l}\text { i firmasının t yılındaki sermayesi } \% 5 \text { 'den büyük } \\
\text { en büyük } 5 \text { ortağının sermaye payının toplam } \\
\text { sermayeye oranı }\end{array}$ \\
\hline $\begin{array}{l}\text { Kurumsal } \\
\text { Ortak }\end{array}$ & $\mathrm{KO}_{\text {it }}$ & $\begin{array}{l}\text { i firmasının t yılındaki sermayesi } \% 5 \text { 'den büyük } \\
\text { kurumsal ortağının sermaye payının toplam } \\
\text { sermayeye oranı }\end{array}$ \\
\hline Yabancı Ortak & $\mathrm{YO}_{\text {it }}$ & $\begin{array}{l}\text { i firmasının t yılındaki sermayesi } \% 5 \text { 'den büyük } \\
\text { yabancı ortağının sermaye payının toplam } \\
\text { sermayeye oranı }\end{array}$ \\
\hline $\begin{array}{l}\text { Halka Açıklık } \\
\text { Oranı }\end{array}$ & $\mathrm{HAO}_{\text {it }}$ & $\begin{array}{l}\text { i firmasının t yılındaki fiili dolaşımdaki pay } \\
\text { tutarının toplam sermayeye oranı }\end{array}$ \\
\hline Aktif Karlılığı & $\mathrm{RO}$ & $\begin{array}{l}\text { i firmasının t yılındaki net kârının toplam } \\
\text { varlıklara oranı }\end{array}$ \\
\hline Büyüklük & Size $_{i t}$ & $\begin{array}{l}\text { i firmasının t yılındaki toplam varlıklarının doğal } \\
\text { logaritması }\end{array}$ \\
\hline Büyüme & Growth $_{\text {it }}$ & $\begin{array}{ll}\text { i firmasının t yılındaki satışlarındaki } & \text { büyüme. } \\
\left(\left(\text { Satışlar }_{\mathrm{t}}-\text { Satışlar }_{\mathrm{t}-1}\right) / \text { Satışlar }_{\mathrm{t}-1}\right) & \text { şeklinde } \\
\text { hesaplanmıştır. } & \end{array}$ \\
\hline
\end{tabular}

Kurulan modelde sahiplik yapısını temsil eden değişkenler ve firma sermaye yapısını temsil eden bağımlı değişken arasındaki ilişkinin incelenmesi amaçlanmıştır. Bu durumda modelde yer alan ROA, Size ve Growth değişkenlerinin kontrol değişkenleri olduğu ifade edilebilir. Söz konusu kontrol değişkenleri de yapılan literatür incelemesi sonucunda firmaların sermaye yapılarına etki ettiği tespit edilen firma karakteristikleri oldukları için seçilmiştir (Zhaoguo ve Xiaoxia 2009; Brailsford, Oliver ve Pua 2002; Sayman 2012).

\subsection{Hipotezler}

Literatürde yapılan çalışmalar incelendiğinde sermaye yoğunlaşmasının olduğu yani sahipliğin az sayıda kişi ya da grubun elinde bulunması 
durumunda firma sahiplerinin yönetici esnekliğini azaltmak, yöneticileri kontrol altına almak için, borçlanmayı bir mekanizma olarak kullanabilecekleri belirtilmiştir (Driffield, Mahambare ve Pal 2007; Céspedes, González ve Molina 2010; Margaritis ve Psillaki 2010). Bu durumda sermaye yoğunlaşması olan firmaların sahiplik yapısındaki en büyük ortağın sermayedeki payı ile finansal kaldıraç oranı arasında pozitif yönlü bir ilişki beklenmektedir. Bu beklentiye paralel olarak çalışma kapsamında sahiplik yapısı içindeki en büyük ortağın sermaye payı ile sermaye yapısı arasındaki ilişkinin incelenmesi amacıyla aşağıdaki H1, H2 ve $\mathrm{H} 3$ hipotezleri kurgulanmıştır:

H1: Ortaklık yapısındaki en büyük ortağın (EBO) sermayedeki payı ve finansal kaldıraç oranı arsında pozitif yönlü bir ilişki vardır.

H2: Ortaklık yapısındaki en büyük 3 ortağın (EB3O) sermayedeki payı ile finansal kaldıraç oranı arasında pozitif iliş̧ki vardır.

H3: Ortaklık yapısındaki en büyük 5 ortağın (EB5O) sermayedeki payı ile finansal kaldıraç oranı arasında pozitif ilişski vardır.

Diğer taraftan, yukarıda ifade edilen beklentiye paralel olarak halka açıklık oranının artması ile finansal kaldıraç oranı arasında da negatif bir ilişki öngörülmektedir. Sermaye yoğunluğunun azalması ve halka açıklık oranının artması iki zit durumu ifade etmektedir. Bu nedenle sermaye yapısı yoğunlaşması ve finansal kaldıraç oranı arasında beklenen pozitif ilişkinin tersi yönde bir ilişki beklenmektedir. Söz konusu beklentinin test edilmesi amacıyla $\mathrm{H} 4$ hipotezi kurgulanmıştır.

H4: Firmaların halka açıklık oranı (HAO) ile finansal kaldıraç oranı arasinda negatif ilişki vardir.

Pushner (1995) çalışmasında da kurumsal yatırımcıların ortak oldukları firmaların finansal kaldıraç oranının düşük olduğunu, kurumsal ortak yoğun firmaların borçluluk oranlarının diğer firmalara göre daha düşük olduğu ifade edilmiştir. Benzer şekilde Kumar (2004) yabanc1 yatırımcıların da kurumsal ortak gibi, ortak oldukları firmaların diğer firmalara göre düşük kaldıraç oranına sahip oldukları belirtilmiştir. Söz konusu bulgulardan yola çıkarak kurumsal ortak, yabancı ortak ve sermaye yapısı arasındaki ilişkilerin incelenmesi amacıyla H5 ve H6 hipotezleri kurulmuştur.

H5: Ortaklık yapısındaki kurumsal ortağın sermayedeki payı (KO) ile finansal kaldıraç oranı arasında negatif iliş̧ki vardır.

H6: Ortaklık yapısındaki yabancı ortağın sermayedeki payı (YO) ile finansal kaldıraç oranı arasında negatif iliş̧ki vardır. 
İfade edilen altı hipotez de, firmaların sahiplik yapıları farklı perspektiflerden ölçülerek sermaye yapısı ile ilişkilerini incelemeye yönelik kurgulanmıştır.

\section{Analiz ve Bulgular}

\subsection{Tanımlayıcı İstatistikler}

Değişkenlere ait tanımlayıcı istatistikler Tablo 2'de sunulmuştur.

Tablo 2: Tanımlayıcı İstatistikler

\begin{tabular}{|l|c|c|c|c|c|c|}
\hline & Ortalama & Ortanca & En Yüksek & En Düşük & Std. Sapma & $\boldsymbol{N}$ \\
\hline FL & 0,23 & 0,22 & 0,89 & 0,00 & 0,19 & 685 \\
\hline EBO & 0,50 & 0,49 & 0,99 & 0,03 & 0,25 & 685 \\
\hline EB3O & 0,62 & 0,65 & 0,99 & 0,05 & 0,22 & 685 \\
\hline EB5O & 0,64 & 0,66 & 0,99 & 0,05 & 0,21 & 685 \\
\hline HAO & 0,32 & 0,28 & 0,93 & 0,01 & 0,20 & 685 \\
\hline KO & 0,50 & 0,60 & 0,99 & 0,00 & 0,32 & 685 \\
\hline YO & 0,14 & 0,00 & 0,99 & 0,00 & 0,28 & 685 \\
\hline ROA & 0,05 & 0,04 & 0,46 & $-0,28$ & 0,09 & 685 \\
\hline Size & 19,71 & 19,59 & 24,16 & 15,76 & 1,56 & 685 \\
\hline Growth & 0,12 & 0,08 & 4,68 & $-0,61$ & 0,29 & 685 \\
\hline
\end{tabular}

Tablo 2 incelendiğinde analize konu olan firmaların borçluluk oranı \%23 düzeyindedir. $\mathrm{Bu}$ veriden yola çıkarak inceleme grubunda yer alan firmaların toplam varlıklarının \%23'ünü yabancı kaynakla finanse ettikleri ifade edilebilir. Aynı zamanda firmaların sermaye yapılarının daha çok özkaynak ağırlıklı olduğu göze çarpmaktadır. Sermayede $\% 5$ veya daha fazla paya sahip ortakların yapısı incelendiğinde, en büyük ortağın toplam sermayeye oranının \%50 düzeyinde, en büyük 3 ortağın payının \%62 düzeyinde, en büyük 5 ortağın payının $\% 64$ düzeyinde olduğu tespit edilmiştir. Firmaların halka açıklık oranının ise inceleme grubu ve dönemi dikkate alınarak ortalama \%32 düzeyinde olduğu görülmektedir. Firmalardaki kurumsal ortak pay1 da ortalama $\% 50$ düzeyindedir. İncelenen firmaların çoğunlukla en büyük ortaklarının (EBO, EB3O, EB5O) kurumsal ortak olmalarının kurumsal ortaklık oranının $\% 50$ düzeyinde olmasına neden olduğu değerlendirilmektedir. Diğer ortaklık paylarına nazaran sermayede $\% 5$ üzerinde payı olan yabanc1 ortak oranı ortalama $\% 14$ düzeyindedir. İnceleme grubunda yer alan firmaların inceleme döneminde satışlarının \%12 oranında artış gösterdiği tespit edilmiştir. Firmaların toplam varlıklarının doğal logaritma değerleri ortalama 19,71 olarak hesaplanmıştır. İncelenen firmaların dönemde aktif kârlılığı da ortalama $\% 5$ düzeyinde 
gerçekleşmiştir. Çalışmada kullanılan değişkenler arasındaki korelasyon bulguları Tablo 3'de sunulmuştur.

Tablo 3: Korelasyon Bulguları

\begin{tabular}{|c|c|c|c|c|c|c|c|c|c|c|}
\hline & $\vec{I}$ & $\begin{array}{l}0 \\
\text { 皇 }\end{array}$ & $\begin{array}{l}\text { O } \\
\text { 皇 }\end{array}$ & $\begin{array}{l}0 \\
0 \\
0 \hat{x}\end{array}$ & $\stackrel{0}{\underline{I}}$ & $\stackrel{\vartheta}{*}$ & $\stackrel{0}{\circ}$ & 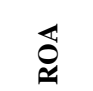 & $\stackrel{8}{5}$ & t) \\
\hline FL & 1 & & & & & & & & & \\
\hline ЕВО & $-0,12 * * *$ & 1 & & & & & & & & \\
\hline EB3O & $-0,12^{* * * *}$ & $0,85^{* * * *}$ & 1 & & & & & & & \\
\hline EB5O & $-0,09 * *$ & $0,81 * * *$ & $0,98 * * *$ & 1 & & & & & & \\
\hline HAO & $0,10 * * *$ & $-0,60^{* * *}$ & $-0,74 * * *$ & $-0,78 * * *$ & 1 & & & & & \\
\hline ко & $-0,15^{* * * *}$ & 0,79 *** & 0,79 **** & $0,76^{* * *}$ & $-0,59 * * *$ & 1 & & & & \\
\hline yo & $-0,10^{* * * *}$ & $0,42 * * *$ & $0,42 * * *$ & $0,42^{* * *}$ & $-0,38^{* * * *}$ & $0,45^{* * *}$ & 1 & & & \\
\hline ROA & $-0,40^{* * * *}$ & $0,12 * * *$ & $0,16 * * *$ & $0,16^{* * *}$ & $-0,21$ **** & $0,15^{* * * *}$ & $0,17 * * *$ & 1 & & \\
\hline Size & $0,22 * * *$ & $0,20 * * *$ & $0,25 * * *$ & $0,24 * * *$ & $-0,31 * * *$ & $0,39 * * *$ & $0,10 * * *$ & $0,10^{* * * *}$ & 1 & \\
\hline Growth & 0,05 & $-0,09 * *$ & $-0,08 * *$ & $-0,06^{*}$ & $0,07 * *$ & $-0,11 * * *$ & $-0,00$ & $0,11^{* * *}$ & $-0,05$ & 1 \\
\hline
\end{tabular}

Not: *, **, *** sırasıyla $\% 10, \% 5$ ve $\% 1$ düzeyinde anlamlı sonuçları ifade etmektedir.

Tablo 3'de raporlanan korelasyon bulgularına göre sermaye yapıs1 temsilcisi olan finansal kaldıraç oranı ve sahiplik yapısı temsilcileri arasında istatistiksel olarak anlamlı bulguların yer aldığı görülmektedir. Finansal kaldıraç oranı ile firmaların halka açıklık oranı dışındaki sahiplik yapısı temsilcileriyle negatif, halka açılık oranı ile de pozitif yönlü korelasyon bulguları tespit edilmiştir. Buradan yola çıkarak sahiplik yapısı ve finansal kaldıraç düzeyi arasında genel olarak negatif ilişki olduğu ifade edilebilir.

Korelasyon bulguları kapsamında dikkat çeken diğer husus ise sahiplik yapısı temsilcilerinin kendi içinde yüksek korelasyon değerlerine sahip olmalarıdır. Tablo 3 incelendiğinde altı temsilci arasındaki korelasyon değerlerinin $-0,38$ ile 0,98 arasında değiștiği görülmektedir. Bağımsız değişkenler arasındaki yüksek korelasyonun genellikle çoklu bağımlılık (multicollinearity) sorununa işaret ettiği değerlendirilmektedir. $\mathrm{Bu}$ sorunun tespitinde temel gösterge olarak kabul edilen değişkenlere ait VIF değerlerinin dikkate alınması gerekmektedir (Gujarati 2009). Raporlanmayan bulgulara göre sahiplik yapısı temsilcilerinin bir kısmının eşik değer olarak kabul edilen 5 ila 10'u aşan VIF değerlerine sahip 
oldukları görülmüştür. Ancak çalışma kapsamında sahiplik yapısı temsilcilerinin modellerde tek başına yer alacağı için söz konusu problem çalışma kapsamında oluşmayacaktır. Altı sahiplik yapısı temsilcisi her bir hipotezin testinde inceleme modelinde diğer sahiplik yapısı temsilcileri olmadan analizler yapilacaktır.

\subsection{Analiz Bulguları}

Korelasyon analizinin ardından çalışma kapsamında ifade edilen hipotezlerin test edilmesi amacıyla regresyon analizi gerçekleştirilmiştir. Kurulan modelde yer alan sermaye yapısı ve firma karakteristikleri dışında sahiplik yapısını ifade eden temsilciler yer almakta ve bu sayede sahiplik yapısının diğer firma karakteristikleri kontrol altındayken sermaye yapısı üzerindeki etkisi ve arasındaki ilişkilerin incelenmesi amaçlanmaktadır. $\mathrm{Bu}$ kapsamda yapılan regresyon analizinden elde edilen bulgular Tablo 4'de sunulmuştur.

Tablo 4: Regresyon Analizi Bulguları

\begin{tabular}{|l|c|c|c|c|c|c|c|}
\hline & & $\mathrm{H} 1$ & $\mathrm{H} 2$ & $\mathrm{H} 3$ & $\mathrm{H} 4$ & $\mathrm{H} 5$ & $\mathrm{H} 6$ \\
\hline $\mathrm{C}$ & $\beta$ & $-0,36$ & $-0,36$ & $-0,35$ & $-0,45$ & $-0,48$ & $-0,36$ \\
\hline EBO & $\mathrm{p}$ & 0,00 & 0,00 & 0,00 & 0,00 & 0,00 & 0,00 \\
\hline & $\beta$ & $-0,09$ & - & - & - & - & - \\
\hline EB3O & $\mathrm{p}$ & 0,00 & - & - & - & - & - \\
\hline & $\beta$ & - & $-0,10$ & - & - & - & - \\
\hline EB5O & $\mathrm{p}$ & - & 0,00 & - & - & - & - \\
\hline & $\beta$ & - & - & $-0,07$ & - & - & - \\
\hline HAO & $\mathrm{p}$ & - & - & 0,00 & - & - & - \\
\hline & $\beta$ & - & - & - & 0,09 & - & - \\
\hline KO & $\mathrm{p}$ & - & - & - & 0,01 & - & - \\
\hline & $\beta$ & - & - & - & - & $-0,12$ & - \\
\hline YO & $\mathrm{p}$ & - & - & - & - & 0,00 & - \\
\hline & $\beta$ & - & - & - & - & - & $-0,04$ \\
\hline ROA & $\mathrm{p}$ & - & - & - & - & - & 0,06 \\
\hline & $\beta$ & $-0,91$ & $-0,90$ & $-0,91$ & $-0,90$ & $-0,88$ & $-0,92$ \\
\hline Size & $\mathrm{p}$ & 0,00 & 0,00 & 0,00 & 0,00 & 0,00 & 0,00 \\
\hline & $\beta$ & 0,03 & 0,03 & 0,03 & 0,03 & 0,04 & 0,03 \\
\hline Growth & $\mathrm{p}$ & 0,00 & 0,00 & 0,00 & 0,00 & 0,00 & 0,00 \\
\hline & $\beta$ & 0,07 & 0,07 & 0,07 & 0,07 & 0,06 & 0,08 \\
\hline Adj. R & $\mathrm{p}$ & 0,00 & 0,00 & 0,00 & 0,00 & 0,00 & 0,00 \\
\hline F stat. (prob) & & 0,24 & 0,24 & 0,24 & 0,24 & 0,27 & 0,23 \\
\hline
\end{tabular}

Tablo 4'de raporlanan bulgular test edilen altı hipotez kapsamında kurulan alt1 modele aittir. Kurulan modellerde yer alan kontrol değişkenlerine ait katsayılar ve anlamlılık değerleri dikkate alındığında 
her modelde varlık kârlılığı (ROA) değişkeninin kaldıraç düzeyi üzerinde negatif ve anlamlı bir etkisinin olduğu görülmektedir.

Diğer taraftan yüksek finansal kaldıraç derecesine sahip firmaların katlanmak durumunda oldukları faiz giderleri de yüksek olacaktır. Bu nedenle varlık kârlılığı değişkeninin negatif bir katsayıya sahip olduğu değerlendirilmektedir. Diğer taraftan varlık büyüklüğü (Size) ve satışlardaki büyüme (Growth) değişkenlerinin her modelde pozitif ve anlamlı katsayılara sahip olduğu görülmektedir. Satışları büyüyen ve büyük ölçekli olan firmaların yeni yatırımlar ve büyüme konusundaki firsatları değerlendirmek için yabancı kaynaklara yönelme istekleri söz konusu katsayıların nedeni olarak değerlendirilebilir.

Tablo 4 H1 sütununda raporlanan değerler çalışma kapsamında test edilen H1 hipotezine aittir ve ortaklık yapısındaki en büyük ortağın (EBO) sermayedeki payı ile finansal kaldıraç oranı arasında pozitif ilişki vardır şeklinde ifade edilmiştir. Tablo 4'de raporlanan değerlerden yola çıkarak elde edilen bulguların H1 hipotezini desteklemediği görülmektedir. Elde edilen bulgular beklentinin tam tersi bir sonucu ortaya çıkarmıştır. Bu durum firmaların ortaklık yapısındaki en büyük ortağının sermaye payı yükseldikçe finansal kaldıraç oranının düştüğü şeklinde yorumlanabilmektedir.

Test edilen ikinci hipotez $\mathrm{H} 2$ hipotezidir ve ayn1 adlı sütunda raporlanmıştır. H2 hipotezi ortaklık yapısındaki en büyük 3 ortağın (EB3O) sermayedeki payı ile finansal kaldıraç oranı arasında pozitif ilişki vardır şeklinde ifade edilmiştir. Tablo 4'de raporlanan değerlerden yola çıkarak elde edilen bulguların H2 hipotezini desteklemediği görülmektedir. Elde edilen bulgulara göre beklenen durumun tam tersi bir sonuç ortaya çıkmıştır. Bu durum da firmaların ortaklık yapısındaki en büyük 3 ortağın sermayedeki payı arttıkça finansal kaldıraç oranının düştüğü şeklinde yorumlanabilir.

En büyük ortağın sermayedeki payı ve sermaye yapısı arasındaki ilişkiyi inceleyen diğer hipotez $\mathrm{H} 3$ hipotezidir. Bu hipotez ortaklık yapısındaki en büyük 5 ortağın (EB5O) sermayedeki payı ile finansal kaldıraç oranı arasında pozitif ilişki vardır şeklinde ifade edilmiştir. Tablo 4'de raporlanan değerlerden yola çıkarak elde edilen bulguların H3 hipotezini desteklemediği görülmektedir. Elde edilen bulgular kurulan hipotezin tam tersi yönündedir. Bu durum da ortaklık yapısındaki en büyük 5 ortağın sermayedeki payı arttıkça finansal kaldıraç oranının düştüğü şeklinde yorumlanmaktadır.

H4 hipotezinde ise firmaların halka açıklık oranları ile finansal kaldıraç oranı arasındaki ilişki incelenmiştir. Bu hipotez firmaların halka açıklık 
oranı (HAO) ile finansal kaldıraç oranı arasında negatif ilişki vardır şeklinde ifade edilmiştir. Tablo 4'de raporlanan değerlerden yola çıkarak elde edilen bulguların H4 hipotezini desteklemediği görülmektedir. Elde edilen bulgular beklentinin tam tersi yönünde bir sonucu ortaya çıkarmıştır. Buna göre firmaların halka açıklık oranı arttıkça finansal kaldıraç oranlarının da arttığıdır.

H5 hipotezinde firmaların ortaklık yapılarındaki kurumsal ortaklık düzeyi ve sermaye yapısı arasındaki ilişki incelenmiştir. Bu hipotez ortaklık yapısındaki kurumsal ortağın sermayedeki payı (KO) ile finansal kaldıraç oranı arasında negatif ilişki vardır şeklinde ifade edilmiştir. Tablo 4'de raporlanan değerlerden yola çıkarak elde edilen bulguların H5 hipotezini desteklediği görülmektedir. Buna göre firma ortaklık yapısındaki kurumsal ortaklığın sermayedeki payı arttıkça finansal kaldıraç oranı azalmaktadır.

Çalışma kapsamında test edilen son hipotez H6 hipotezidir ve ortaklık yapısındaki yabancı ortağın sermayedeki payı (YO) ile finansal kaldıraç oranı arasında negatif ilişki vardır şeklinde ifade edilmiştir. Tablo 4'de raporlanan değerlerden yola çıkarak elde edilen bulguların H6 hipotezini desteklediği görülmektedir. Buna göre firmaların ortaklık yapısındaki yabancı ortağın sermayedeki payı arttıkça finansal kaldıraç oranı düşmektedir.

\section{Sonuç}

$\mathrm{Bu}$ çalışmada firmaların sahiplik yapısını gösteren ortaklık yapısının sermaye yapısını oluşturan kaynak yapısı üzerindeki etkisi analiz edilmiştir. Çalışma kapsamında BİST İmalat Sektöründe 2012-2016 y1lları arasında faaliyet gösteren 137 firmanın Datastream ve KAP'dan elde edilen 685 firma-yıl verisi kullanılmıştır. Analiz sonucunda temel olarak firmaların sahiplik yapısının sermaye yapısını üzerinde etkisi olduğu belirlenmiştir. $\mathrm{Bu}$ kapsamda değerlendirildiğinde literatürde yapılan çalışmalarla paralellik gösteren sonuçlara ulaşıldığı ifade edilebilir.

Çalışma kapsamında altı hipotez test edilmiştir. Bu hipotezlerin ilk üçü (H1, H2 ve H3) ortaklık yapısındaki en büyük ortağın sermayedeki pay1 ve sermaye yapısı arasındaki ilişkileri test etmeye yöneliktir. Bu kapsamda elde edilen bulgulara göre firmaların ortaklık yapısındaki en büyük ortağın sermayedeki payı arttıkça finansal kaldıraç oranlarının azaldığı tespit edilmiştir. Firmaların halka açıklık oranı ve sermaye yapısı arasındaki ilişkileri incelemek üzere kurulan H4 hipotezinden elde edilen bulgular da firmaların halka açıklık oranı arttıkça finansal kaldıraç 
oranlarının da arttığını göstermektedir. Buradan yola çıkarak inceleme döneminde firmaların büyüme firsatlarını değerlendirmek için ihtiyaç duydukları finansı hem özkaynak hem de dış borç yoluyla temin ettikleri ifade edilebilir. Firmaların ortaklık yapılarındaki kurumsal ortağın sermaye payı ve sermaye yapısı arasındaki ilişkilerin incelenmesi amaciyla kurulan H5 hipotezi kapsamında elde edilen bulgulara göre ise sermayedeki kurumsal ortağın payının artması, firmaların finansal kaldıraç oranlarını azaltmaktadır. Söz konusu bulguya göre kurumsal ortağın daha düşük finansal kaldıraç oranına sahip firmaları tercih ettiği ya da ortağı olduğu firmanın finansal kaldıraç oranının azalması yönünde hareket ettiği ifade edilebilir. Çalışmada test edilen son hipotez olan H6 hipotezinde firma ortaklık yapısındaki yabancı ortağın sermayedeki payı ve sermaye yapısı arasındaki ilişkiler incelenmiştir. H6 hipotezi kapsamında elde edilen bulgulara göre firmanın ortaklık yapısındaki yabancı ortağın sermayedeki payı arttıkça firmaların finansal kaldıraç oranları azalmaktadır. Bu durumda da kurumsal ortak yapısına benzer şekilde yabancı ortağın daha düşük finansal kaldıraç oranına sahip firmalara ortak olmayı tercih ettikleri ya da ortağı olduğu firmaların daha düşük finansal kaldıraç oranına sahip olmaları yönünde hareket ettikleri değerlendirilmektedir.

Firmaların daha az paydaşın elinde olması durumu sermaye yoğunlaşması şeklinde ifade edilebilir. Sermaye yoğunlaştıkça finansal kaldıraç oranının azaldığı tespit edilmiştir. Vekalet teorisine göre firma yöneticisi paydaşların değerini en yükseğe çıkarma amacına hizmet etmek üzere yetkilendirilmektedir. Böyle bir durumda yöneticinin paydaş çıkarları yerine kendi menfaatleri doğrultusunda davranması vekalet sorununu oluşturacaktır. Teoriye göre böyle bir durumda firmanın borçlandırılması sayesinde borç verenlerin de firmayı izleyecekleri ve bu sayede vekalet sorununun ortadan kalkacağı düşünülmektedir. Ancak çalışma kapsamında elde edilen bulgular vekalet teorisini desteklememektedir. Firmalarda sermaye yoğunlaşması oldukça finansal kaldıraç oranının düştüğü tespit edilmiştir. Sermaye yapısı ve sahiplik yapısı arasındaki ilişkilerin incelendiği literatür dikkate alındığında bu iki değişken arasında pozitif ilişki bulunduğuna yönelik sonuçlar elde eden çalışmaların (Brailsford, Oliver ve Pua 2002; Driffield, Mahambare ve Pal 2007; Margaritis ve Psillaki 2010) yanı sıra negatif ilişki veya ilişkisiz sonuçlar bulunan çalışmaların (Li, Yue ve Zhao 2009; Mehran, Taggart ve Yermack 1999; Santos, Moreira ve Vieira 2014) olduğu da görülmektedir. Dolayısıyla yapılan çalışmalardan elde edilen sonuçların sektör, bölge ve dönemsel açıdan farklılıklar gösterdiği ifade edilebilir. 
Sermaye yapısı ile sahiplik yapısı arasındaki ilişkileri inceleyen bu çalışmanın bazı kısıtları bulunmaktadır. Analiz bulguları 2012-2016 yılları arasında BİST'de işlem gören imalat firmaları açısından geçerlidir. Gelecek dönemde yapılacak çalışmaların söz konusu bulgu farklılıklarının nedenlerini ortaya çıkaracak bir yapıda kurgulanmasının faydalı olacağı düşünülmektedir. Bu sayede gelişmiş ve gelişmekte olan ülkeler arasındaki, sektörler ve dönemler arasındaki farklılıklar açıklanabilir.

\section{Kaynaklar}

Ayrıçay, Yücel, ve Göktürk Kalkan. (2013) "Sahiplik Yapısı ve Temsilcilik Teorisi." Kahramanmaraş Sütçü Imam Üniversitesi Iktisadi ve İdari Bilimler Fakültesi Dergisi 3.2: 153-74.

Bayrakdaroğlu, Ali. (2010) "Mülkiyet Yapısı ve Finansal Performans: İMKB Örneği." Ekonomi Bilimleri Dergisi 2.2.

Brailsford, Timothy J, Barry R Oliver, ve Sandra LH Pua. (2002) "On the Relation between Ownership Structure and Capital Structure." Accounting \& Finance 42.1: 1-26.

Büyükmert, N. (2015) İşletmelerde Sahiplik Yapısının Kârlılık Ve Sermaye Yapısı Üzerine Etkileri: Borsa Istanbul'da Ampirik Bir Uygulama. Yayımlanmamış Yüksek Lisans Tezi. Balıkesir: Balıkesir Üniversitesi Sosyal Bilimler Enstitüsü.

Céspedes, Jacelly, Maximiliano González, ve Carlos A Molina. (2010) "Ownership and Capital Structure in Latin America." Journal of Business Research 63.3: 248-54.

Çinko, Murat, ve Oytun Tansel Kasaboğlu. (2017) "Kurumsal Sahiplik İle Sermaye Yapısı Arasındaki İlişki Üzerine Bir Çalışma: Türkiye Örneği." Marmara İktisat Dergisi 1.2: 155-70.

Demsetz, Harold, ve Kenneth Lehn. (1985) "The Structure of Corporate Ownership: Causes and Consequences." Journal of Political Economy 93.6: 1155-77.

Doğan, Mesut. (2016) "Mülkiyet Yapisinin Finansman Kararlari Üzerindeki Etkisi." Muhasebe ve Finansman Dergisi.70.

Doğan, Mesut. (2016) "Yönetici ve Yabancı Sahipliğinin Sermaye Yapısı Üzerindeki Etkileri: Bİst'te Işlem Gören Imalat Sanayi Firmaları Üzerine Bir Araştırma." Yönetim Bilimleri Dergisi 14.28: 49-69. 
Driffield, Nigel, Vidya Mahambare, ve Sarmistha Pal. (2007) "How Does Ownership Structure Affect Capital Structure and Firm Value? Recent Evidence from East Asia." Economics of Transition 15.3: 535-73.

Ege, İlhan, ve Tuğba NUR Topaloğlu. (2013) "Sahiplik Yapısının Sermaye Yap1s1 Kararlarına Etkisi: Borsa İstanbul'da Bir Uygulama." Anemon Muş Alparslan Üniversitesi Sosyal Bilimler Dergisi 5.2: 471-92.

Erdoğan, Eda Oruç. (2016) "Temsil Teorisi Çerçevesinde Sahiplik Yapısının İşletmelerin Sermaye Yapısı Kararları Üzerine Etkİsİ: BİST Uygulamas1." Journal of Suleyman Demirel University Institute of Social Sciences 24.2.

Gujarati, Damodar N. (2009) Basic Econometrics. Tata McGraw-Hill Education.

Karacaer, Semra, Hüseyin Temiz, ve Ömer Faruk Güleç. (2016) "Determinants of Capital Structure: An Application on Manufacturing Firms in Borsa Istanbul." International Academic Journal of Accounting and Financial Management 3.2: 47-59.

Kartal, Mustafa Tevfik. (2017) Finansal Yönetim-Temel Teoriler ve Açıklamalı Örnekler. Sermaye Yapısı. Ed. Gündoğdu, Aysel: Seçkin Yayıncılık.

Kester, W Carl. (1986) "Capital and Ownership Structure: A Comparison of United States and Japanese Manufacturing Corporations." Financial Management: 5-16.

Kumar, J. (2004) "Debt Vs. Equity: Role of Corporate Governance." 8th Capital Markets Conference, Mumbai: Indian Institute of Capital Markets.

Li, Kai, Heng Yue, ve Longkai Zhao. (2009) "Ownership, Institutions, and Capital Structure: Evidence from China." Journal of Comparative Economics 37.3: 471-90.

Margaritis, Dimitris, ve Maria Psillaki. (2010) "Capital Structure, Equity Ownership and Firm Performance." Journal of Banking \& Finance 34.3: 621-32.

Mehran, Hamid, Robert A Taggart, ve David Yermack. (1999) "Ceo Ownership, Leasing, and Debt Financing." Financial Management: 5-14. 
Pushner, George M. (1995) "Equity Ownership Structure, Leverage, and Productivity: Empirical Evidence from Japan." Pacific-Basin Finance Journal 3.2-3: 241-55.

Santos, Mário Sacramento, António Carrizo Moreira, ve Elisabete Simões Vieira. (2014) "Ownership Concentration, Contestability, Family Firms, and Capital Structure." Journal of Management \& Governance 18.4: 1063-107.

Sayman, Yahya. (2012) Sahiplik Yapısinin Firma Performansı Ve Sermaye Yaplsı Üzerine Etkileri: İmkb'de Işlem Gören Üretim Firmalarında Bir Uygulama. Yayınlanmamış Doktora Tezi. Ankara: Ankara Üniversitesi Sosyal Bilimler Enstitüsü.

Zhaoguo, Zhang, ve Liu Xiaoxia. (2009) "The Effects of Capital Structure on Earnings Management: Empirical Evidence from China." 1st International Conference on. IEEE. Information Science and Engineering (ICISE). 